EESTI NSV TEADUSTE AKADEEMIA TOIMETISED. VI KOIDE BIOLOOGILINE SEERIA. 1957, NR. 3

ИЗВЕСТИЯ АКАДЕМИИ НАУК ЭСТОНСКОЙ ССР. ТОМ · VI

СЕРИЯ БИОЛОГИЧЕСКАЯ. 1957, 스 3

\title{
LEHISEVÄHI ESINEMINE EESTI NSV-S
}

\section{MUISTE}

Lehisevähk on ohtlikumaid lehise seenhaigusi. Ulatuslikumalt esineb ta Lääne- ja Kesk-Euroopas, kus ta kahjustab euroopa lehist $[1,2,3,4,6$. NSV Liidu territooriumil esineb lehisevähki üldiselt vähe, kuid kohati (Uraalis, Siberis) põhjustab ta küllaltki suurt kahju [ $\left.{ }^{2}\right]$.

Eesti NSV-s märgiti lehisevähi esinemist esmakordselt 1941. aasta sügisel praeguse Eesti Põllumajanduse Akadeemia Järvselja õppe- ja katsemetsamajandis kvartalil 222. 1943. aastaks, mil esmakordselt ilmus artikkel lehisevähi esinemise kohta Eestis, oli kirjeldatud vaid 7 lehisevähi esinemise juhtu [ $\left.{ }^{2}\right]$. Viimastel aastatel on lehisevähk üsna ulatuslikult levinud ja näiteks Järvseljal võib teda pidada päris tõsiseks puistute kahjustajaks, eriti euroopa lehise osas. Ka teistes metskondades võib lehisevähi kahjustusi tähele pan-

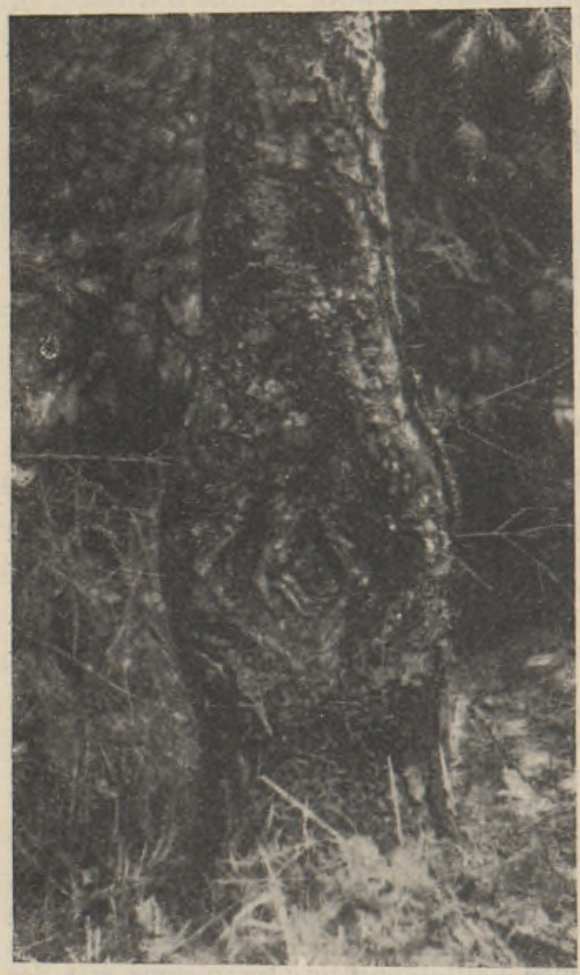

Foto 1. Lehisevähi (Dasyscypha Willkommii Hart.) kahjustus euroopa lehise (Larix decidua) tüvel. EPA Järvselja oppe- ja katsemetsamajand, kvartal 273. na: Näiteks Kaarepere metskonna Luua vahtkonnas esines 1955 . aasta kevadel põimendusraiel väljaraiutud lehiste võrades (eriti kuivanud okstel) üsna hulgaliselt lehisevähi tekitaja viljakehi. Dots. P. Rõika andmeil esineb Roela metskonna lehisepuistus tugevaastmeline lehisevähi kahjustus. Kuna meil lehise kasvupind aasta-aastalt laieneb, on vaja pöörata lehisevähi esinemisele ja tõrjele senisest suuremat tähelepanu.

Lehisevähi põhjustajana on üldiselt tuntud ketasseen Dasyscypha Willkommii Hart., mis nakatab puid peamiselt kuivanud okste kaudu $\left[{ }^{2}, 5,8\right]$. Algul vegeteerib seen saprofüüdina, kuid hiljem, tungides kuivanud okstelt elavasse tüvesse, muutub parasiidiks ja tekitab tüvel vähihaavandeid. Seenemütseel vegeteerib koores rakkudevahelises ruumis, kust ta puiduni tungides surmab kambiumi. Kahjustuskohal koor kuivab. Vegetatsiooniperioodil intensiivistub elusate kambiumirakkude kasv kahjustuskoha ümber ja nad moodustavad madala vallitaolise puidukihi ümber vähihaavandi. Peamiselt sügisel, kui seene kasv on kõige hoogsam, surmab seenemütseel havandi ümber 
tekkinud elusrakud, mille tulemusena vähihaavand laieneb aasta-aastalt üsna selgete kontsentriliste ringidena. Sageli esineb vähihaavandi ümbruses vähest vaiguvoolu. Kahjustuskohal muutub puu kasv ekstsentriliseks ning tüvi jämeneb haavandi külgedel ja vastasküljel (foto 1 ja 2). Vähihaavand takistab mahlade liikumist puul, nõrgendab puu kasvu ning viib lõpuks puu kuivamisele. Vähihatavandi tōttu surnud koorel arenevad mõnemillimeetrilise läbimõõduga alustassikujulised valged viljakehad (apoteetsiumid) (foto 3 ), kus valmivad seene eoskotid kotteostega.

Kirjanduses leidub ka seisukohti, et lehisel esineb kaks erinevat Dasyscypha liiki: Dasyscypha Willkommii Hart. obligatoorse parasiidina ja Dasyscypha calycina Fuck. obligatoorse saprofüüdina $[3,4,6]$. Selguse saamiseks sellesse küsimusse koguti 26. oktoobril 1956. aastal EPA Järvselja õppe- ja katsemetsamajandi euroopa lehise puistutest haigusetekitaja seene viljakehi nii kasvavatelt kui ka kuivanud puudelt. Kogutud materjalil mõõdeti kohe apoteetsiumide diameetrid ja eoskottide ning kotteoste pikkused ja laiused., Uldse mõõdeti 244 apoteetsiumi, 150 kotteost ja 61 eoskotti. Mõõtmistulemused surnud ja eluspuudelt kogutud materjalidel märgiti eraldi ning on esitatud tabelis 1 .

Mõōtmine näitas, et kasvavatelt puudelt pärinevate viljakehade diameetrid on väiksemad (lahter 2), aga eoskotid ja kotteosed suuremad (lahtrid 3-6), võrreldes kuivanud puudelt kogutud ja mõõdetud viljakehadega. Soomes korraldatud uurimistel [6] on saadud analoogilisi tulemusi, kusjuures kotteoste mõotmed on V. Kujala järgi vaid üsna vähe suuremad, vorrreldes tabelis 1 toodud andmetega. Kuigi mõõtmiste arvu vähesuse tõttu ei või teha lõplikku järeldust, näib siiski olevat tõenäoline, et ka meil on tegemist kahe erineva lehisevähki põhjustava seene liigiga. Nendest eluspuudel vegeteeriv liik Dasyscypha Willkommii Hart. põhjustab tüüpilisi vähihaavandeid (foto 1), kuna kuivanud puudel ja rädil esinev Dasyscypha calycina Fuck. neid ei tekita (foto 4). Antud küsimuse

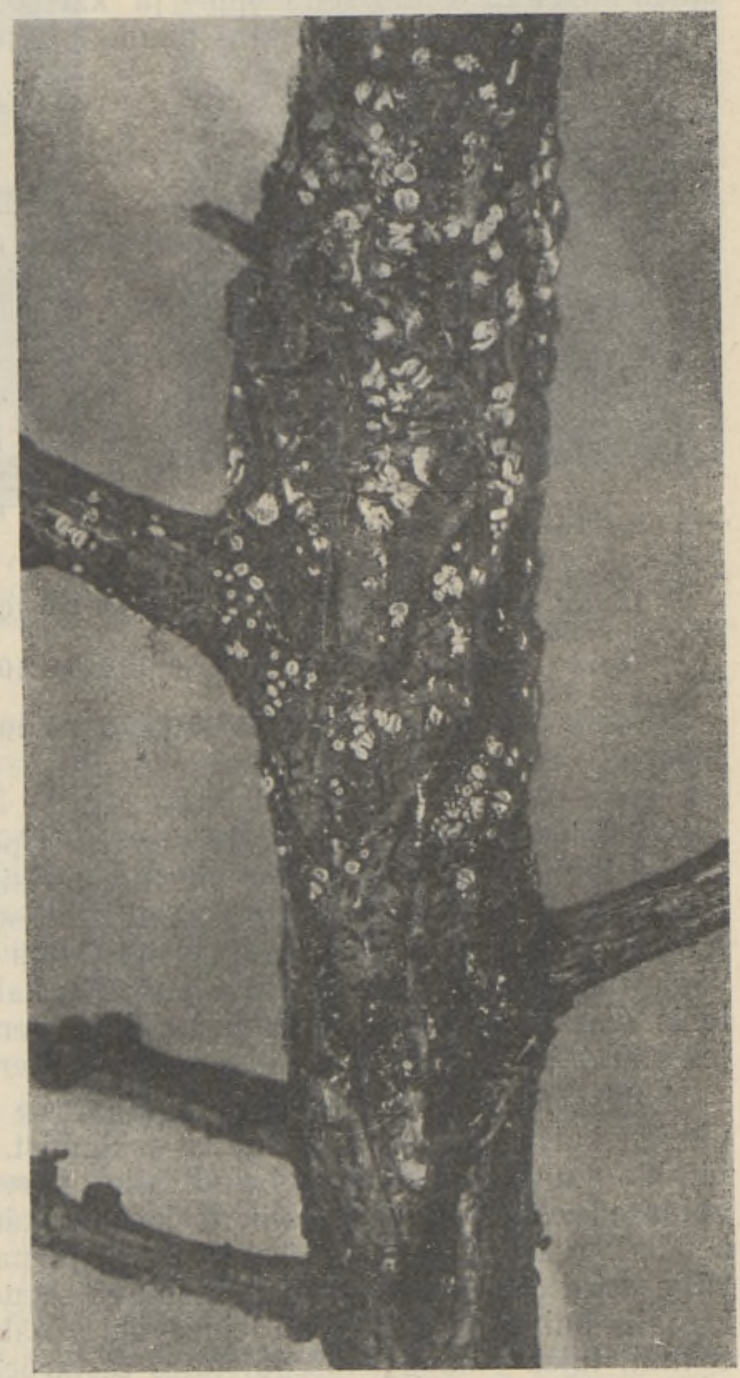

Foto 2. Lehisevähi (Dasyscypha Willkommii Hart.) tekitatud haavand noore lehise tüvel. EPA metsakasvatuse ja metsakultuuride kateedri kogudest. 
L. Muiste

Tabel 1

\begin{tabular}{|c|c|c|c|c|c|}
\hline \multirow[b]{2}{*}{ Materjal kogutud } & \multirow{2}{*}{$\begin{array}{c}\text { Viljakehade } \\
\text { keskmine } \\
\text { diameeter } \\
(\mathrm{mm})\end{array}$} & \multicolumn{2}{|c|}{ Eoskottide keskmine } & \multicolumn{2}{|c|}{ Kotteoste keskmine } \\
\hline & & pikkus $(\mu)$ & laius $(\mu)$ & pikkus $(\mu)$ & laius $(\mu)$ \\
\hline 1 & 2 & 3 & 4 & 5 & 6 \\
\hline $\begin{array}{l}\text { Kasvavatelt puudelt } \\
\text { Kuivanud puudelt }\end{array}$ & $\begin{array}{c}1,34 \\
(0,6-3,0) \\
1,84 \\
(0,7-3,6)\end{array}$ & $\begin{array}{c}131,2 \\
(110-162) \\
117,2 \\
(90-138)\end{array}$ & $\begin{array}{c}14,0 \\
(11-17) \\
11,8 \\
(9-15)\end{array}$ & $\begin{array}{c}20,3 \\
(13,2-28,4) \\
16,0 \\
(10,5-22,0)\end{array}$ & $\begin{array}{c}7,6 \\
(6,3-9,5) \\
6,2 \\
(4,2-8,1)\end{array}$ \\
\hline
\end{tabular}

edasine uurimine on väga vajalik, sest sellest sõltub ka otstarbekohase tõrjeviisi väljatöötamine.

Lehisevähi kahjustuse ulatuse ja iseloomu selgitamiseks korraldati 1955. aasta suvel EPA Järvselja õppe- ja katsemetsamajandis euroopa, vene ja kuriili lehise puistute ülevaatus pụude kasvuklasside kaupa. Selle tulemused esitatakse tabelis 2 .

Tabel 2

\begin{tabular}{|c|c|c|c|c|c|c|c|c|c|c|c|c|c|c|c|c|}
\hline \multirow{3}{*}{ 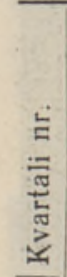 } & \multirow{3}{*}{ Puu liik } & \multirow[b]{3}{*}{ 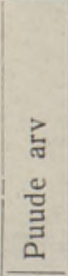 } & \multirow{3}{*}{ 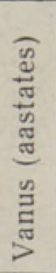 } & \multicolumn{3}{|c|}{ Keskmine } & \multicolumn{10}{|c|}{$\begin{array}{c}\text { Tervete ja haigete puude jagunemine } \\
\text { (kasvuklassis) }\end{array}$} \\
\hline & & & & & $\widehat{\mathbb{E}}$ & & I & & II & & II & & IV & & V & \\
\hline & & & & 胥 & ב⿱艹 & 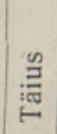 & 竞 & 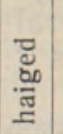 & 芯 & 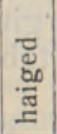 & 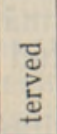 & 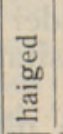 & 总 & 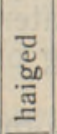 & $\begin{array}{l}\vec{D} \\
\stackrel{0}{2} \\
\end{array}$ & \\
\hline 1 & 2 & 3 & 4 & 5 & 6 & 7 & 8 & 9 & 10 & $\overline{11}$ & 12 & 13 & 14 & 15 & 16 & 17 \\
\hline 273 & $\begin{array}{l}\text { Euroopa lehis } \\
\text { (Larix decidua) } \\
\text { Vene lehis } \\
\quad \text { (Larix rossica) } \\
\text { Kuriili lehis } \\
\text { (Larix kurilensis) }\end{array}$ & $\begin{array}{r}103 \\
69\end{array}$ & $\begin{array}{l}24 \\
28\end{array}$ & $\begin{array}{l}13,0 \\
16,0\end{array}$ & $\begin{array}{c}12,0 \\
15,5\end{array}$ & $\begin{array}{l}0,8 \\
1,0\end{array}$ & $\begin{array}{l}100 \\
100\end{array}$ & -1 & $\begin{array}{c}89 \\
100\end{array}$ & $\begin{array}{l}11 \\
-\end{array}$ & 100 & $\begin{array}{l}19 \\
-\end{array}$ & $\begin{array}{r}69 \\
100\end{array}$ & $\begin{array}{l}31 \\
-\end{array}$ & $\begin{array}{l}- \\
- \\
-\end{array}$ & 100 \\
\hline
\end{tabular}

Nii tabeli andmete kui ka teistes lehisepuistutes tehtud tähelepanekute põhjal ilmneb kahjustuse intensiivsuses üksikute kasvuklasside piirides teatav seaduspärasus. Kõige tugevamini kahjustavad vähiseened kasvus teistele allajäänud puid (IV, V kasvuklassis), kuna I kasvuklassi puud kannatavad väga juhuslikult. Lehiseliikidest kannatab kahjustuse all kõige enam euroopa lehis (Larix decidua), tunduvalt vähem vene lehis (Larix rossica), kuriili lehis (Larix kurilensis) on aga tavaliselt terve.

Lehisevähi tõrjeks on vaja regulaarselt organiseerida hooldusraieid, et vältida kuivavate puude hulgalist tekkimist. Igal hooldusraiel tuleb täpselt jälgida puude tervislikku seisundit ning kõrvaldada kõik haiged puud. Kuna viimased esinevad peaasjalikult kasvus kängujäänud puude hulgas, siis nende kõrvaldamisel ei teki puistusse lubamatuid auke. Kuni ei ole lõplikult välja selgitatud lehisevähki põhjustava seene liik, on eriti vajalik raiekoha korralik puhastus, et vältida lehisevähi viljakehade massilist tekkimist rädil. Samuti tuleb pidada lehisepuistutes otstarbekohaseks kuivanud okste laasimist, sest need võivad olla nakkuse koldeks ${ }^{[2}$. Paljudel juhtudel meie metskondades teostatakse hooldusraieid lehisepuistutes kas liiga tagasihoidlikult või üldse mitte. Hooldusraietele lehisepuistutes tuleb aga kõikjal pöörata senisest palju tõsisemat tähelepanu. 


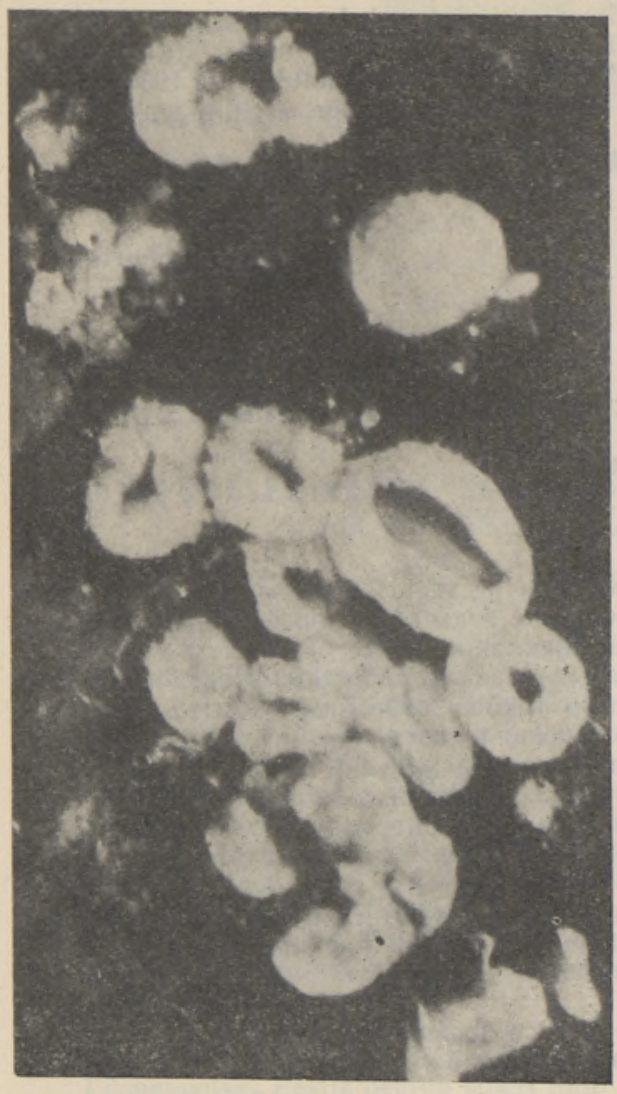

Foto 3. Lehisevähi tekitaja (Dasyscypha Willkommii Hart.) viljakehad (apoteetsiumid). Suurendatud ligikaudu 8 korda.

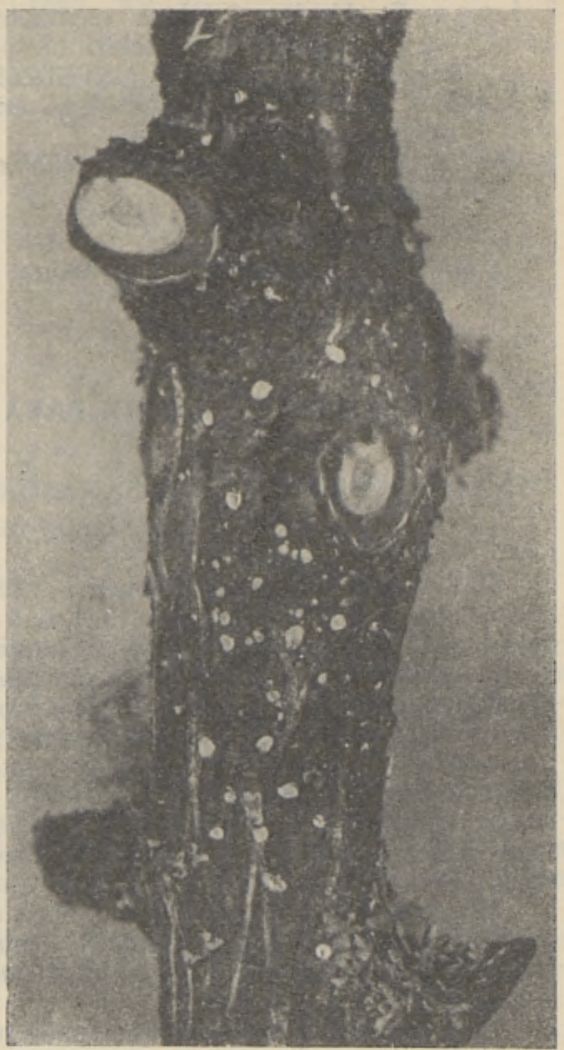

Foto 4. Dasyscypha calycina Fuck, viljakehad kuivanud lehise tüvel. EPA metsakasvatuse ja metsakultuuride kateedri kogudest.

Lehisevähi vältimiseks tuleks võimalust mööda juba lehisekultuuride rajamisel arvestada lehiseliigi valikut. Nii tuleks kasutada võimalikult rohkem neid lehiseliike, mis kannatavad vähem lehisevähi all. Kuna kuriili lehis on selles suhtes praktiliselt immuunne ning näitab meie oludes suurepärast kasvu $\left.{ }^{[}\right]$, siis peaks just seda liiki enam kultiveerima. Kahtlematult on väga oluline ka otstarbekohase kultuuritüübi valik. Segakultuurides on hõlpsam hooldusraietega kindlustada lehisele vajalik kasvuruum.

\section{KIRJANDUS}

1. В а н и н С. И., Лесная фитопатология. Третье издание. М.-Л., 1948.

2. В а н ин С. И., Лесная фитопатология. Издание четвертое, посмертное (переработанное и дополненное). М.-Л., 1955.

3. H a h n, G. G. and Ayer s, T. T., Dasyscyphae on Conifers in North America I. The Large-spored, White-excipled Species, Mycologia, vol. XXVI, 1934, No. 1.

4. H a h n, G. G. and Ay ers, T. T., The European Larch Canker and its Relation to Certain Other Cankers of Conifers in the United States. Journal of Forestry, vol. XXXIV, 1936, No. 10.

5. H es s-B e ck, Forstschutz. Neudamm, 1930.

6. Ku ja la, V., Uber die Kleinpilze der Koniferen in Finnland. Metsätieteellisen Tutkimuslaitoksen Julkaisuja 38, (4), 1950. 
7. L a a s, E., Uurimusi lehise seemnete kvaliteedist ja otstarbekast kasutamisest Eesti NSV tingimustes. Väitekiri bioloogiateaduste kandidaadi teadusliku kraadi taotlemiseks. Käsikiri Eesti NSV Teaduste Akadeemia Keskraamatukogus. 1956.

8. Neger, F. W., Die Krankheiten unserer Waldbäume und der wichtigsten Gartengehölze. Stuttgart, 1924.

9. O st r a t, A., Lehisevähi Dasyscypha Willkommii Hart. leidudest Eestis. Eesti Mets, 1943 , nr. 7.

Eesti Pöllumajanduse Akadeemia

Saabus toimetusse

6. III 1957

\title{
О РАСПРОСТРАНЕНИИ РАКА ЛИСТВЕННИЦЫ В ЭСТОНСКОИ ССР
}

\author{
Л. Ю. Муйсте
}

Резюме

Рак лиственницы обнаружен в учебно-опытном лесхозе Ярвселья Эстонской сельскохозяйственной академии в $1941 \mathrm{r}$. и за последнне годы он довольно широко распространился в лиственничных насаждениях республики.

В целях выяснения вида гриба, вызывающего рак лиственницы, в октябре 1956 г. проводились измерения апотеций, сумок и спор грибов, собранных в учебно-опытном лесхозе Ярвселья ЭСХА. В результате этих измерений выяснилось, что у гриба, произрастающего на растущих деревьях, диаметры апотеции меньше (табл. 1, графа 2), а сумки и споры больше (графы 3-6), чем у гриба, собранного с сухостоя. Исходя из результатов измерений и данных, опубликованных в литературе [ $\left.{ }^{6}\right]$, является достоверным наличие двух разных видов - Dasyscypha Willkommii Hart. и Dasyscypha calycina Fuck.

Из различных видов лиственницы больше всех страдает от этой болезни лиственінца европейская (Larix decidua), значительно меньше лиственница русская (Larix rossica), а лиственница курильская (Larix kurilensis) обычно совсем не поражена этой болезнью.

Для борьбы с раком лиственницы рекомендуется проводить регулярно рубки ухода и при закладке культур пользоваться по возможности более стойкими к этой болезни видами лиственницы.

$\begin{array}{cc}\text { Эстонская } & \text { Поступила в редакцию } \\ \text { сельскохозяйстенная академия } & 6 \text { III } 1957\end{array}$

\section{ON LARCH CANKER IN'THE ESTONIAN SSR}

\section{Muiste}

\section{Summary}

Larch canker was discovered at the Teaching and Experimental Station Järvselja of the Estonian Agricultural Academy in 1941 and it has spread rather widely in larch plantations during recent years.

In order to clear up the problem of the fungus species causing larch canker the measurement of apothecia, asci and ascospores of the fungus collected at the Teaching and Experimental Station Järvselja of the Estonian Agricultural Academy was carried out in October 1956. As a result of the measurement it was found that the diameter of apothecia on growing trees was smaller (Table 1, column 2), but the asci and ascospores were bigger (columns 2-6) when compared with the corresponding data collected and measured on dead trees. According to the data of investigation and literature used [6] it seems probable that there are two different species, viz. Dasyscypha Willkommii Hart. and Dasyscypha calycina Fuck.

Among the larch species the European larch (Larix decidua) suffers from injury most, the Russian larch (Larix rossica) considerably less, whereas the Kuril larch (Larix kurilensis) is usually unaffected (Table 2).

In combating larch canker it is advisable to carry out regular felling and to use as many disease-resistant species of larch as possible in starting the plantation of the culture. 